\title{
Do Vale para o Vale: uso colaborativo dos meios como forma de reforçar vínculos
}

\section{Raíssa Fernandes Faria}

Universidade Federal de Minas Gerais | Brasil raissaff@gmail.com

\section{Tomás German}

Universidade Federal de Minas Gerais | Brasil tomasspgerman@gmail.com

\section{José Henrique Pires}

Universidade Federal de Minas Gerais | Brasil jhpazevedo@gmail.com

\section{Resumo}

0 artigo desenvolve algumas perspectivas para discutir como as oficinas de comunicação, realizadas no Programa de Férias, coordenado pelo Polo de Integração da UFMG no Vale do Jequitinhonha (Proex/UFMG) e pelo Laboratório de Relações Públicas Plínio Carneiro (Larp/UFMG), estimulam o reconhecimento e a valorização da região por parte dos jovens moradores do Vale do Jequitinhonha que participam das atividades. Na primeira parte do texto, nos propomos a discutir três eixos: o uso dos meios, a produção de comunicação colaborativa e o espaço local. $\mathrm{Na}$ segunda, apresentaremos algumas das oficinas desenvolvidas no Programa de Férias com vistas a exemplificar o debate acerca do uso colaborativo dos meios como forma de reforçar vínculos de pertencimento na relação entre sujeitos e seu espaço local.

\section{Palavras-chave}

Comunicação; Juventudes; Acesso aos meios; Colaboração; Local. 


\section{Introdução}

0 presente texto ${ }^{1}$ é resultado de um esforço de reflexão e sistematização acerca das oficinas de comunicação desenvolvidas no Vale do Jequitinhonha, nordeste de Minas Gerais, por meio do Programa de Férias, coordenado pelo Polo de Integração da Universidade Federal de Minas Gerais (UFMG) no Vale do Jequitinhonha,² vinculado à Pró-Reitoria de Extensão (PROEX/UFMG), e pelo Laboratório de Relações Públicas Plínio Carneiro (Larp), do curso de Comunicação Social da UFMG. ${ }^{3}$ Desenvolvido durante as férias escolares, nos meses de janeiro e julho, o Programa de Férias visa a responder as demandas por formação e empoderamento oriundas dos coletivos juvenis e culturais da região. Para tanto, mobiliza bolsistas dos Projetos e Programas vinculados ao Polo, ${ }^{4}$ bem como voluntários dos cursos de Comunicação Social, Letras, Artes e Arquitetura, especialmente, para o desenvolvimento de oficinas de comunicação.

O Programa de Férias tem por orientação não apenas instrumentalizar os jovens, mas, sobretudo, fomentar o debate acerca do uso dos meios, da produção colaborativa e do reforço de vínculos com o espaço local. As oficinas de comunicação organizam e resultam de interações e trocas simbólicas, em um processo marcado pelo fazer mídia e o que se faz com ela, ou seja, por uma aprendizagem que se dá em meio a processos simbólicos que organizam trocas e solicitam participação e comprometimento. Da mesma forma, as oficinas consideram a realidade socioeconômica e cultural do Vale do Jequitinhonha, em especial, o desejo e/ou a necessidade de migração dos jovens. Nesse sentido, estimula-se o vínculo com o local, a partir do debate sobre sua importância.

O intuito deste artigo é propor uma reflexão acerca dos movimentos almejados durante a condução das oficinas, quais sejam: aproximação, apropriação e adequação de suportes e protocolos às possibilidades e interesses dos coletivos juvenis atendidos. Para tanto, incentivase a prática tentativa, visando à definição de um formato, por uma parte, e de enfrentamento de dificuldades e desafios que concretamente se colocam durante o processo, por outra. Como salienta Braga (2007, p. 5 [grifo no original]), "nas áreas em que não dispomos de conhecimentos suficientemente consolidados, os processos de aprendizagem social são mais frequentes e diversificados - porque são vinculados aos contextos imediatos em que se desenvolvem, e porque são tentativos". É importante considerar, todavia, que o fazer tentativo não se encontra dissociado dos processos mediatizados, referenciais não apenas para a mídia, mas também para campos e atores sociais diversos.

$\mathrm{Na}$ primeira parte do texto, nos propomos a discutir três eixos: o uso dos meios, a produção de comunicação colaborativa e o espaço local. Na segunda, apresentaremos algumas 
Do Vale para o Vale: uso colaborativo dos meios como forma de reforçar vínculos

das oficinas desenvolvidas no Programa de Férias, com vistas a exemplificar o debate acerca do uso colaborativo dos meios como forma de reforçar vínculos.

\section{0 que se faz com os meios de comunicação}

As oficinas de comunicação oferecidas pelo Programa de Férias partem da reflexão sobre o acesso e o uso dos meios. 0 acesso é apresentado como direito garantido pela Declaração Universal dos Direitos Humanos: "o direito de todas as pessoas de ter acesso aos meios de produção e veiculação de informação e cultura, de possuir condições técnicas e materiais para ouvirem e serem ouvidas e de ter o conhecimento necessário para estabelecer uma relação autônoma e independente frente aos meios de comunicação" (Observatório do Direito à Comunicação). Nesse sentido, as oficinas de comunicação vêm ao encontro de uma política de democratização do acesso público à comunicação.

Tendo em vista, primeiramente, o acesso instrumental, as oficinas possibilitam aos jovens o contato com softwares gratuitos e livres e com equipamentos de produção de baixo custo. Entretanto, pensa-se na democratização da comunicação para além do fornecimento instrumental dos meios, não considerando os recursos técnicos como "algo, por si só, capaz de transformar as relações sociais" (COUTINHO, 2008, p. 8). O debate se desloca, assim, do acesso aos meios de comunicação para uma esfera complementar, ao indagar os jovens acerca do uso que pretendem dar aos meios. Ou seja: acesso para quê? Com qual finalidade? Para que usos?

Um dos pontos centrais das oficinas do Programa de Férias é levar os integrantes dos coletivos juvenis a refletir sobre o que pretendem fazer com os meios de que dispõem (ou passam a dispor). Dessa forma, por uma parte, os sujeitos são incitados a propor outros modos de olhar e fazer, tendo o local como centro, enquanto, por outra, incentiva-se a autonomia para sua efetiva participação no uso da mídia e, consequentemente, nos processos de transformação de suas localidades.

Esse processo de fomento à autonomização dos sujeitos e à democratização do acesso e do uso dos meios potencializa uma participação cidadã nas questões referentes aos contextos sociocultural e econômico locais. Para tanto, as oficinas de comunicação são organizadas de modo a estimular a participação colaborativa dos jovens, objetivando o fazer comunicação por meio dessa perspectiva.

0 acesso aos meios vem acompanhado de um método que

[...] respeite e estimule a criatividade de cada indivíduo, que se baseie na construção coletiva e dialógica do conhecimento, valorizando os saberes dos participantes, a experimentação, o lúdico, que estimule a autonomia, que contribua com a participação do sujeito e de sua participação ativa nos processos cotidianos de transformação da sociedade (MELO et al, 2006, p. 45). 
Do Vale para o Vale: uso colaborativo dos meios como forma de reforçar vínculos

Ao considerar a discussão sobre o uso da mídia, mesmo que restrita ao grupo que participa diretamente do Programa de Férias, e a presença mediática no espaço social, característica dessa época de "sociedade mediática", as oficinas de comunicação pretendem fazer com que "a sociedade se perceba 'conversando' consigo mesma” (BRAGA, 2001, p. 21).

\section{Os processos colaborativos}

As atividades do Programa de Férias, assim como as demais atividades de comunicação realizadas pelo Polo, valorizam o aspecto colaborativo, que promove o compartilhamento de responsabilidades entre os jovens participantes. As ações são executadas coletivamente, mantendo um diálogo constante entre os jovens e os educadores durante os processos formativos e de produção. Na metodologia colaborativa, são valorizados os trabalhos em equipe, que estimulam a criatividade de cada participante, suas ideias, experiências e conhecimentos individuais.

Nesse processo, cabe à equipe do Polo apresentar os recursos midiáticos e, por meio de processos formativos, permitir que os jovens experimentem esses recursos. Dessa forma, os participantes são colocados como protagonistas da produção, enquanto a equipe de educadores se torna apenas facilitadora. A atuação no Programa de Férias tem permitido à equipe do Polo construir uma metodologia de formação atenta a um esforço pedagógico lúdico e experimental no tocante à apropriação dos fazeres midiáticos. Embora tal discussão sobre o caráter lúdico seja importante, ela não será aqui aprofundada.

Cabe ressaltar que os métodos colaborativos utilizados não são imutáveis. Pelo contrário, as atividades são desenvolvidas de acordo com as demandas e realidades dos sujeitos que participam de cada oficina. Os produtos são esboçados previamente, mas sofrem alterações e são modificados na medida em que os jovens apresentam suas ideias e sugerem novas formatações para eles.

São os jovens que efetivamente produzem, sugerindo pautas, fazendo entrevistas, fotografias e gravações, etc. Eles são responsáveis por produzir e selecionar todo o conteúdo dos produtos, bem como por formatá-los. "Quando convocamos o outro a se posicionar reconhecemos nele a corresponsabilidade pelo jogo. Queremos que ele assuma um papel ativo e se reconheça como origem de atos, normas e princípios da ação conjunta" (MELO et al., 2006 p. 61). A intenção é despertar a autonomia e o sentimento de responsabilidade pelo que está sendo produzido.

Para além de desenvolver a autonomia e o empoderamento, o método colaborativo também é fundamental para desenvolver o sentimento de corresponsabilidade nos jovens. Esse 
Do Vale para o Vale: uso colaborativo dos meios como forma de reforçar vínculos

sentimento está relacionado ao nível de engajamento dos integrantes em determinada causa, alcançado por meio de ações para mobilização social (HENRIQUES, 2007). ${ }^{5}$ A comunicação tem papel fundamental no processo de mobilização social, que é entendida como "uma reunião de sujeitos que definem objetivos e compartilham sentimentos, conhecimentos e responsabilidades para a transformação de uma dada realidade, movidos por um acordo em relação à determinada causa de interesse público" (HENRIQUES, 2007).

Nas oficinas de comunicação, o processo dialógico visa, ainda, ao reconhecimento do espaço local como parte dos sujeitos. Busca-se incentivar, por meio do compartilhamento de experiências, a reelaboração coletiva de questões que permeiam a vida dos jovens e de suas comunidades de origem.

\section{A importância do local}

Para que se defina o papel das oficinas do Programa de Férias no fortalecimento do vínculo com o que está próximo, é preciso, antes de tudo, explicar o que se entende por proximidade. A categoria "proximidade" é construída e, conforme aponta Bourdin (2001), toda configuração de local a mobiliza de forma variada. A proximidade possibilita a percepção e a organização da experiência na ordem das relações sociais e, também, das relações econômicas e políticas. Tem caráter estruturante. A proximidade remete a uma espacialidade social e culturalmente construída, o local, que exprime a pertença a um nós e delimita um recorte territorial.

O conceito de local não é facilmente demarcável. Tampouco é simples balizar o seu lugar contemporaneamente. A localidade pode, às vezes, não passar de uma circunscrição projetada por uma autoridade, em razão de princípios que vão desde a história até critérios puramente técnicos. Em outros casos, ela exprime a proximidade, o encontro diário; em outro, a existência de um conjunto de especificidades sociais e culturais bem partilhadas (BOURDIN, 2001, p. 25); num quarto, de inserção e partilha (PERUZZO, 2003, p. 68).

O local pode ser entendido como um espaço restrito, delimitado, vivido, em que há elos de proximidade e familiaridade (PERUZZO, 2002 e 2003; Ortiz, 1999 e s/d; FEATHERSTONE, 1997), mas que não se encontra isolado ou separado de um conjunto. O local pode ser potencializado pelas seguintes dimensões:

a) Proximidade: o sentido de proximidade diz respeito à noção de pertencimento, ou dos vínculos existentes entre pessoas que partilham de um cotidiano e de interesses em comum.

b) Singularidade: cada localidade possui aspectos específicos, tais como a sua história, os costumes, valores, problemas, língua etc., o que, no entanto, não dá ao local um caráter homogêneo.

c) Diversidade: o local comporta múltiplas diferenças e a força de pequenas unidades. 
Do Vale para o Vale: uso colaborativo dos meios como forma de reforçar vínculos

d) Familiaridade: constituída a partir das identidades e raízes históricas e culturais (PERUZZO, 2003, p. 78).

Segundo Ortiz (s/d, p. 59), "quando nos referimos ao 'local', imaginamos um espaço restrito, bem delimitado, no interior do qual se desenrola a vida de um grupo ou de um conjunto de pessoas. Ele possui um contorno preciso, a ponto de se tornar baliza territorial para os hábitos cotidianos. 0 "local" se confunde assim com o que nos circunda". 0 local, segundo essa abordagem, associa-se à comunidade.

Objetivado também como território, o local é um modo organizador da experiência: “O local coloca em forma o mundo da vida diária, sendo ele próprio fundador da relação com o mundo do indivíduo, mas igualmente da relação com o outro, da construção comum do sentido que faz o vínculo social" (BOURDIN, 2001, p. 36). Também, a geografia e a história oferecem códigos que auxiliam na identificação de especificidades locais, a partir de determinados recortes territoriais.

Nesse sentido, o processo de construção das oficinas se baseia na busca de referências locais e na valorização do que é do local. Desse modo, a visibilidade de grupos e personagens das cidades, os locais e até a apropriação dos espaços físicos são elementos fundamentais. Lança-se um olhar mais minucioso para a cultura, para a geografia e para a história das comunidades por onde passamos. A seguir, explicaremos mais detalhadamente como a valorização do local se dá em cada oficina ministrada pelo Polo, no Vale do Jequitinhonha.

\section{As oficinas de comunicação}

De modo geral, as oficinas são oferecidas a partir das demandas encaminhadas por grupos e coletivos juvenis do Vale do Jequitinhonha ao Programa Polo. Como já foi dito, são ministradas por estudantes da UFMG na condição de educadores. A seguir, destacamos três das nove oficinas desenvolvidas na edição de verão do Programa de Férias 2013.

\subsection{Oficina de Audiovisual}

A oficina de vídeo e edição aconteceu na cidade de Carbonita, município do Vale do Jequitinhonha, com população estimada de 9.148 habitantes, dentre os quais 1.966 têm entre 10 e 19 anos (IBGE, 2010). A cidade abriga o grupo Ponto de Cultura Sementes do Vale, financiado por um projeto federal e vinculado à Prefeitura. 0 coletivo possui uma sede que funciona diariamente, em horário comercial, e que é utilizada para a realização de oficinas e para a promoção do acesso digital e da ampliação de capital social, por meio de um espaço de convivência entre os jovens da cidade. 0 coletivo dispõe de seis computadores, uma televisão e 
Do Vale para o Vale: uso colaborativo dos meios como forma de reforçar vínculos

uma sala com sofás e cadeiras. Desde 2005, o Programa Polo de Integração da UFMG, no Vale do Jequitinhonha, realiza projetos em parceria com o Ponto de Cultura. Os jovens que já tinham o hábito de frequentar o espaço tiveram a oportunidade de se inscrever para a oficina. Ao todo, 21 jovens de Carbonita, entre 12 e 20 anos, participaram de quatro dias da oficina de vídeo e edição, mediada por dois educadores, uma acadêmica de Comunicação Social e um acadêmico de Cinema de Animação, ambos da UFMG.

O município ainda está às margens dos meios de comunicação tradicionais: não possui emissora de TV nem jornal local e tem apenas uma rádio, a Radio Comunitária Lider FM, e um blog, que não é atualizado com frequência. Mediante a discussão do presente trabalho sobre a importância da comunicação local na construção de sentidos e protocolos de interações sociais, evidencia-se a gravidade da exclusão dos moradores de Carbonita à produção e ao consumo de conteúdos que tratem de sua realidade.

Além da falta de acesso local aos meios de comunicação, o município sofre com os altos índices de migração dos jovens, que encontram poucas opções culturais e de emprego e não têm acesso ao ensino superior na cidade. Os relatos dos jovens moradores são, majoritariamente, de sua insatisfação com as opções do município e do interesse em um envolvimento com a cultura dos grandes centros urbanos de Minas Gerais, em detrimento da cultura local.

Diante desse quadro, o projeto se propôs a contribuir para ampliar o acesso aos meios de comunicação no município, para estimular o engajamento e o protagonismo juvenil na cidade e para fortalecer o sentimento de pertencimento dos jovens em relação à região de Carbonita. Para tanto, concretizou-se a oferta de uma oficina de audiovisual, ferramenta que, por suas particularidades, constitui-se em um espaço e em uma prática que envolve os sujeitos, fomentando a autorrealização e a pluralidade. 0 audiovisual é capaz de criar "condições para que algumas pessoas, que não teriam outros modos para se fazerem ouvidas, ocupem a cena pública e enunciem suas perspectivas. Além disso, garante que a população tenha acesso a informações, opiniões e perspectivas" (MENDONÇA, 2010, p. 31). Também possibilita que os sujeitos tornem-se ativos no processo de mediação.

Se a mediação por imagens constitui as relações sociais, então é preciso inserirmo-nos de forma ativa nessa mediação, para que possamos participar efetivamente dessas relações. Um dos caminhos para isso é a experimentação da linguagem e a produção de imagens que, por sua vez, solicitem um olhar mais ativo por parte daqueles que a experimentam (MELO et al., 2006, p. 40).

Partindo disso, a oficina teve como proposta construir, colaborativamente, um produto de audiovisual para que, de fato, os jovens de Carbonita experimentassem o acesso à criação de um produto de comunicação, capaz de valorizar a cultura e o conhecimento locais. Nesse sentido, a oficina foi dividida em seis etapas. 0 primeiro momento foi dedicado à apresentação, por parte 
Do Vale para o Vale: uso colaborativo dos meios como forma de reforçar vínculos

dos educadores, de alguns princípios básicos de filmagem e da exposição de conceitos, como etapas de produção de um vídeo, tipos de plano, possibilidades de enquadramento, de luz e som. Além disso, os educadores buscaram problematizar questões mais globais sobre a comunicação, ampliando a noção da linguagem audiovisual, para além da técnica. Foram promovidas, nesse momento, discussões relacionadas à diferença entre o mero registro de imagem e a construção de uma narrativa audiovisual, os efeitos das escolhas de enquadramentos temáticos, as possibilidades de expressão por meio da produção audiovisual e a padronização das linguagens midiáticas.

O segundo momento foi o da construção da ideia do grupo para a produção do vídeo. É importante destacar que a construção da oficina teve como ponto de partida a noção teórica de comunicação para mobilização (HENRIQUES, 2007). Por isso, a proposta do vídeo não poderia ser determinada a priori pelos educadores. Para a real apropriação do produto final pelos jovens, esses precisariam ser sujeitos ativos no processo de criação desse produto, como afirma Hissa (1994). "Quando se pretende produzir conhecimento junto ao outro - e não sobre o outro será preciso criar, também, junto ao outro, modos de fazer" (1994, p. 128). Assim, com a intenção de incentivar o conhecimento e o envolvimento com a cultura local de Carbonita, os jovens foram instigados pelos mediadores a pensarem sobre o que gostariam de falar sobre eles mesmos e sobre a cidade onde moravam. Ao final da dinâmica, os jovens foram desafiados a categorizar as ideias apresentadas, em um esforço de separá-las em temáticas que tivessem ligações. Ao realizarem esse processo, os participantes eliminaram algumas propostas, criaram novas e sugeriram a divisão em dois eixos temáticos principais e, assim, em dois vídeos distintos. Esse processo da proposição e criação do tema foi parte essencial da proposta formativa da oficina, que se centra muito mais nos processos do que nos produtos finais em si. A terceira etapa foi a captação das imagens. No quarto momento, foram passadas as noções básicas de edição de vídeos, utilizando-se de software livre e de fácil aprendizado para a edição. 0 quinto momento foi o da edição e finalização dos produtos. E o último momento foi o da apresentação dos vídeos em um espaço cultural da cidade, com a presença dos pais e convidados dos jovens, como forma de partilhar a produção colaborativa e "mostrar" a cidade aos seus habitantes.

\subsection{Oficina de Produção para Web - Portfólio Digital}

Durante o Programa de Férias, edição do verão de 2013, foi ministrada a oficina de Produção para Web - Portfólio Digital ${ }^{6}$, no município de Araçuaí, que tem população estimada em 36.013 habitantes, dentre os quais 7.313 são jovens entre 10 e 19 anos (IBGE, 2010). A oficina foi ofertada para 15 jovens de dois grupos culturais da região, o Coral Araras Grandes e a Cia. de Teatro Ícaros do Vale. Com exceção de um dos participantes, todos os demais tinham 
Do Vale para o Vale: uso colaborativo dos meios como forma de reforçar vínculos

entre 13 e 24 anos. O Coral Araras Grandes e a Cia. de Teatro Ícaros do Vale são grupos conhecidos por apresentarespetáculos ligados à cultura do Vale do Jequitinhonha e à valorização do seu povo. A demanda para a oficina partiu da Cia. de Teatro Ícaros do Vale em razão da necessidade de criar um portfólio online para o Grupo. 0 produto foi elaborado no Wix, plataforma digital que oferece ferramentas para desenvolver sites e os hospeda de forma gratuita. A oficina foi ministrada por três acadêmicos de Comunicação Social.

A primeira etapa da oficina foi voltada, principalmente, para o processo formativo, em que se buscou apresentar aos jovens a definição do que é um portfólio digital e a linguagem da internet e, ainda, demonstrar o manuseio das ferramentas da plataforma Wix. Durante esses momentos, os jovens se sentiram à vontade para compartilhar seus conhecimentos, tornando o processo mais coletivo.

Em seguida, os jovens se dividiram em quatro equipes, assumindo as atividades específicas para criação do portfólio, quais sejam: equipe de edição de site, responsável por definir layout, configurar o site e estruturar as páginas; equipe de separação do arquivo, responsável por coletar todo o arquivo em fotos e vídeos do grupo de teatro; equipe de produção de textos, para produzir a história do grupo e o perfil dos participantes; e outra equipe de texto, para produzir a ficha técnica dos espetáculos já apresentados pelo Ícaros do Vale e, também, pensar nas formas de divulgação do produto.

As funções das equipes foram pensadas, anteriormente, pelos educadores, como forma de otimizar o tempo. No final do primeiro dia de oficina, os jovens de cada equipe elaboraram um planejamento das atividades que iriam desenvolver e apresentaram aos demais participantes. Dessa forma, todos tiveram a oportunidade de entender o processo completo de criação do portfólio.

Durante o segundo dia de atividades, os grupos foram monitorados de perto pelos educadores, que apenas acompanharam o trabalho e solucionaram as dúvidas que surgiram. No terceiro dia, os jovens seguiram com a produção e iniciaram o processo de postagem do conteúdo no site. Essa etapa exigiu maior atenção por parte dos educadores, que orientaram os jovens para utilização das ferramentas do Wix.

Para a divulgação do produto, os jovens pensaram em uma mobilização pelas redes sociais, principalmente no Facebook, por meio da veiculação do portfólio na página da Cia. de Teatro Ícaros do Vale e de um lançamento oficial na loja Vale com Valor, um estabelecimento que vende artigos feitos por grupos culturais do município e da região. No lançamento aberto ao público, que aconteceu no último dia de oficina, os jovens apresentaram o site e contaram sobre a experiência na oficina. 
Do Vale para o Vale: uso colaborativo dos meios como forma de reforçar vínculos

No percurso de elaboração do portfólio, os jovens se envolveram em atividades que exercitaram diferentes habilidades. 0 grupo de edição elaborou o layout, a partir da discussão sobre a utilização de cores e sobre a disposição de elementos visuais e textuais nas páginas. 0 grupo responsável pelo acervo desenvolveu a pesquisa, coleta e separação de arquivos antigos da Cia. Ícaros do Vale. Também foram trabalhadas, mesmo que de forma mais superficial, algumas técnicas de entrevistas e fotografias para a construção de perfis dos artistas. Outra habilidade bastante estimulada foi a produção de textos: fichas técnicas, informações, histórico, entre outros. Os textos foram revisados pelos educadores, que procuravam mostrar a necessidade de adequar a linguagem ao formato web.

No final da oficina, durante a avaliação realizada - parte importante de todas as oficinas do Programa de Férias -, os jovens pensaram na melhor forma de manter e atualizar o portfólio. Foi definido quem seria o responsável pelo site e quem atualizaria as redes sociais do Grupo. Além disso, os jovens discutiram quais elementos devem ser mudados para que o site evolua e não fique desatualizado.

$\mathrm{Na}$ avaliação final com os participantes, foi possível perceber que os jovens se engajaram nas atividades e se sentiram responsáveis pelo produto que estavam desenvolvendo. Esse engajamento foi possível devido à organização do trabalho em equipe, que estimulou e valorizou também o trabalho individual, sem deixá-los alheios à produção como um todo. Outro ponto importante foi a valorização de um grupo de cultura local pelos jovens participantes da oficina.

\subsection{Oficina de Cordel}

Outra oficina ministrada, no município de Araçuaí, foi a de Cordel,7 que envolveu 15 participantes, com idade entre dez e 25 anos, a grande maioria integrante do Quingemm, grupo de percussão da cidade. A oficina visava a ressignificar histórias e lugares a partir da produção de literatura de cordel, bem como da produção de xilogravuras e desenhos para ilustrá-la. Como resultado, foi produzido um livrinho de cordel, distribuído em praça pública ao término da oficina, que teve duração de três dias. A oficina foi ministrada por um acadêmico de Comunicação Social e outro de Arquitetura.

A oficina de cordel teve como ementa a apresentação dessa forma de se comunicar, tão típica da cultura popular brasileira, mas, presente também, em materiais midiáticos de grande circulação. Durante a oficina, os jovens do Jequitinhonha foram estimulados a encarar seu contexto histórico, social, geográfico e político de forma mais crítica e empoderada, por uma parte, e desafiados a espacializar signos, por outra.

A espacialização de signos se deu na promoção de uma deriva, um flâneur pela cidade de Araçuaí. Nessa deriva, os jovens foram instigados a buscar símbolos de suas identidades, 
Do Vale para o Vale: uso colaborativo dos meios como forma de reforçar vínculos

elementos que dizem o que eles são e o que os construiu. Como afirma Walter Benjamim (apud Jacques, 2011, p. 94), a experiência da deriva proporciona um choque entre o individual e o coletivo, o público e o privado, capaz de gerar um bem coletivo e político e o confronto ao status quo.

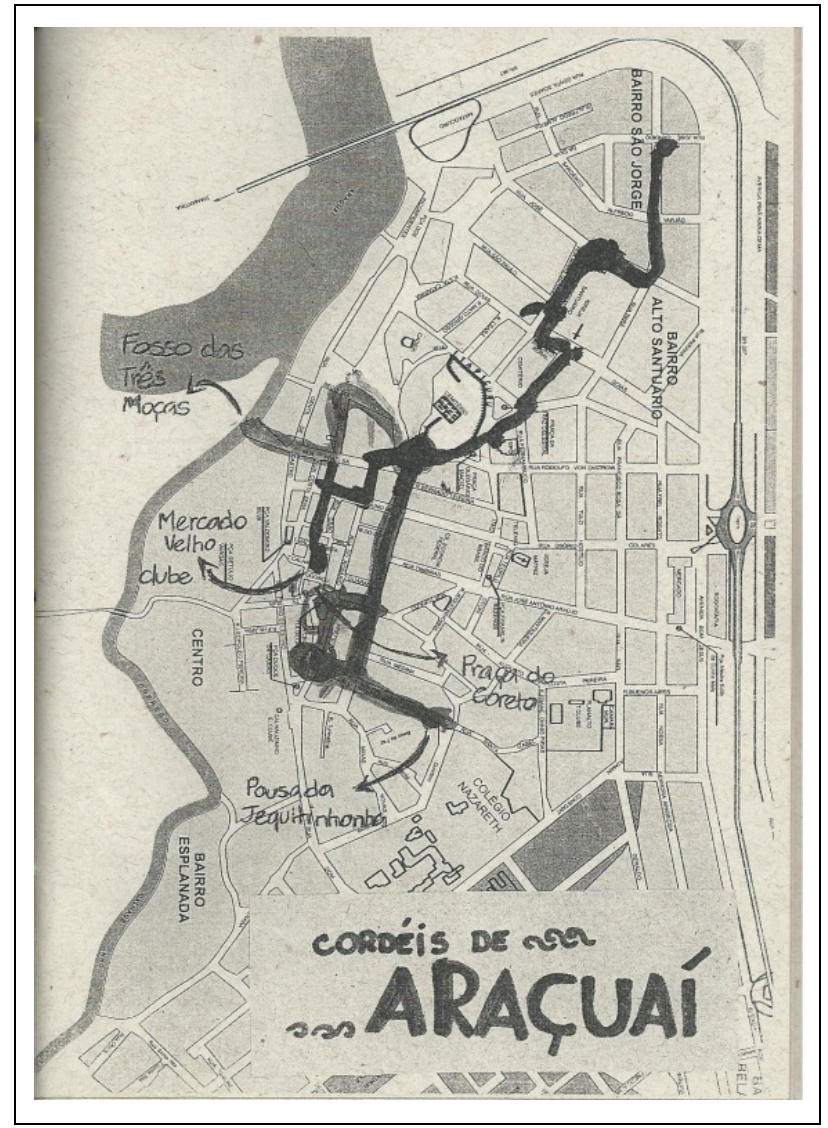

Ilustração 1: Capa do cordel produzido na oficina

Com isso, os jovens foram instigados a conhecer (ou reconhecer) algo na própria cidade, lançando um olhar diferente sobre aquilo que já estavam acostumados a ver. Um olhar sobre o outro que, ao mesmo tempo, é dirigido ao seu interior. Afinal, se a deriva, o flaneur, se materializa pela figura de um labirinto, pelo sentimento de perda, a visão do que é diferente se torna fundamental, e a saída desse labirinto se encontra no próprio sujeito. Só é possível sair do labirinto se o sujeito se encontrar no outro, no que é diferente, para que a diferença e a estranheza deixem de existir.

O Cordel "Dona Onça", criado por alguns jovens participantes da oficina, deixa claro o quanto o confronto com o outro se torna importante para vida social. Depois do contato amistoso com Dona Ana, a Dona Onça, protagonista da história, deixa "de lado tanta amargura e tristeza" e passa a viver melhor e mais alegre. 
Do Vale para o Vale: uso colaborativo dos meios como forma de reforçar vínculos

Também pode ser visto como processo de espacialização de signos o próprio mapa utilizado na abertura do livrinho com os cordéis, que representa, justamente, os caminhos percorridos pelos grupos que escreveram os poemas (Ilustração 1). Depois da atividade de deriva, que consistiu na perda dos caminhos e no contato com diferentes personalidades e locais da cidade, de acordo com o interesse do grupo, os jovens marcaram no mapa onde eles estiveram e por onde passaram; um processo de se localizar, importante para afirmação. Isso porque os mapas funcionam como instrumento do poder. Segundo Marquez (2011, p. 9),

A tradição histórica de excluir algo ou alguém do mapa produziu uma espécie de apagamento, de negação e de incapacidade para o diálogo entre partes do mundo, Do mesmo modo, a operação oposta de incluir algo ou alguém no mapa, de finalmente desenhar mapas inéditos ou de criar condições para que aqueles que não aparecem nos mapas criem os seus próprios mapas constitui uma reescritura e um redesenho do mundo, um passo para uma geografia de coexistências, de diversidade e compartilhamento.

Desse modo, localizar-se no mapa significa afirmar sua identidade perante um espaço que o comporta, que o representa, mas que não lhe é concedido, já que o mapa sem esses jovens significa um apagamento deles. Com isso, a indicação daquilo que foi importante para a escrita da história foi salientado no mapa, para dar destaque àquilo que identificava os jovens. A oficina trabalhou a literatura de cordel e a produção de xilogravuras como forma de ilustrar os poemas e histórias construídas. Contemplou, também, o processo de finalização do livro de cordéis, trabalhando o processo de confecção e costura dos mesmos.

A oficina é ofertada como forma de propor uma produção alternativa de comunicação, com vistas à produção de fanzines. Ao pensar em técnicas baratas de reprodução de textos e ilustrações, a oficina introduz os jovens no universo produtivo das mídias, tornando-os aptos a também produzirem mensagens comunicacionais a partir dos recursos de que dispõem.

\section{Considerações finais}

As oficinas de comunicação do Programa de Férias visam a constituir-se como espaço de debate e estímulo em relação ao uso da comunicação, com vistas ao reconhecimento e à valorização do local - os municípios do Vale do Jequitinhonha -, a partir da ação colaborativa de jovens dessa região, participantes de projetos e/ou coletivos juvenis e culturais. Nesse sentido, como já ressaltando ao longo do texto, é preciso destacar o esforço metodológico das oficinas, cuja formatação objetiva tornar o processo dialógico e interativo, corresponsabilizando os jovens durante todo o processo formativo e produtivo e incentivando-os a um uso cidadão, compartilhado e responsável dos meios. 
Do Vale para o Vale: uso colaborativo dos meios como forma de reforçar vínculos

A experimentação de papéis é também um importante elemento "formador" nas oficinas - tanto para os jovens como para os educadores. A aprendizagem, via de regra, se dá pela possibilidade de uso e interação, pela experimentação tentativa de formatos e processos produtivos, em uma ação permeada por modelos já existentes, por uma parte, e pelo experienciar coletiva e colaborativamente outras possibilidades de uso do meio de comunicação, por outra. Desse modo, a partir de um movimento de aproximação e apropriação de modelos de produção mediática, são instituídos espaços voltados à comunicação dos coletivos atendidos nas oficinas, além de seus municípios de origem.

Por essa perspectiva, as oficinas desafiam os participantes a repensar a importância do espaço local, levando-os a estabelecer (ou reestabelecer) vínculos, que contribuem para o crescimento e empoderamento desses jovens. Tal reflexão colabora, ainda, para o desenvolvimento de uma comunicação voltada para o local, capaz de desafiá-lo e mobilizá-lo - e aos seus sujeitos - em torno de desafios e interesses comuns.

\section{Referências}

BOURDIN, Alain. A questão local. Rio de Janeiro: DP\&A Editores, 2001.

BRAGA, José Luiz. A sociedade enfrenta sua mídia: dispositivos sociais de crítica midiática. São Paulo: Paulus, 2006.

BRAGA, José Luiz. Constituição do Campo da Comunicação. In: FAUSTO NETO, Antonio et al (org.). Campo da Comunicação: caracterização, problematização e perspectivas. João Pessoa: Editora Universitária/UFPB, 2001. p.11-39.

BRAGA, José Luiz. Processos de aprendizagem para uma sociedade de interação mediatizada. 2007. In: REDE PROSUL, 2007, São Leopoldo, RS. Anais eletrônicos... São Leopoldo, RS: Unisinos, 2007.

COUTINHO, Eduardo Granja. Comunicação e contra-hegemonia: processos culturais e comunicacionais de contestação, pressão e resistência. Rio de Janeiro: Editora UFRJ, 2008.

FEATHERSTONE, Mike. 0 desmanche da cultura: globalização, pós-modernismo e identidade. São Paulo: Studio Nobel: SESC, 1997.

HENRIQUES, Márcio Simeone. Comunicação e estatégias de mobilização social. 2. reimp. Belo Horizonte: Autêntica, 2007.

Hissa, Cássio Eduardo Viana. Entrenotas: Compreensões de pesquisa; Belo Horizonte: Editora UFMG, 2013.

JACQUES, P. B. Estética da ginga: A arquitetura das favelas através da obra de Hélio Oiticica. 4. ed. Rio de Janeiro: Casa da Palavra, 2011. 
Do Vale para o Vale: uso colaborativo dos meios como forma de reforçar vínculos

MARTÍN-BARBERO, Jesús. Dos meios às mediações: comunicação, cultura e hegemonia. Rio de Janeiro: Editora UFRJ, 2009.

MELO, Aléxia et al. Metodologia: o jogo e a reinvenção. In: LIMA, Rafaela (org.). Mídias comunitárias, juventude e cidadania. Belo Horizonte: AIC; Autêntica, 2006. p. 35-65.

MENDONÇA, Ricardo Fabrino. Alguns apontamentos em prol do audiovisual comunitário. In: LEONEL, Juliana; MENDONÇA, Ricardo Fabrino (orgs.). Audiovisual comunitário e educação: Histórias, processos e produtos. Belo Horizonte: Autêntica, 2010. p. 23-45.

ORTIZ, Renato. Um outro território: ensaios sobre a mundialização. São Paulo: Editora Olho D’Água, s/d.

ORTIZ, Renato. Um outro território. In: BOLAÑO, César R. S. (org.). Globalização e regionalização das comunicações. São Paulo: EDUC/Editora da UFS/INTERCOM, 1999.

PERUZZO, Cicília M. Krohling. Mídia local e suas interfaces com a mídia comunitária. In: Anuário Unesco/Umesp de Comunicação Regional. n. 6, ano 6, jan./dez.2002. São Bernardo do Campo, SP: Umesp, 2002. p.51-78.

PERUZZO, Cicília M. Krohling. Mídia local, uma mídia de proximidade. In: Comunicação: Veredas. Revista do Programa de Pós-Graduação em Comunicação. n. 2, ano 2, v. 1, nov. 2003. São Paulo: Editora Unimar, 2003. p.65-89.

\footnotetext{
1 Versão revista de trabalho apresentado na IV Conferência Sul-Americana e IX Conferência Brasileira de Mídia Cidadã, em agosto de 2013.

2 Doravante, Polo.

${ }^{3}$ Em 2013, quando da produção deste artigo, os autores eram bolsistas de Extensão do Suporte de Comunicação do Programa Polo de Integração da UFMG no Vale do Jequitinhonha, que era co-coordenado pelos professores doutores Marcio Simeone Henriques e Angela Zamin.

4 O Programa Polo, criado em 1996, se tornou um dos principais programas de extensão da UFMG. Promove a integração de projetos de pesquisa e extensão realizados na região localizada a nordeste de Minas Gerais, cujos municípios distam, em média, 600 quilômetros da capital do estado. A região é notória não apenas por suas carências, mas também por uma rica cultura, pelo seu processo histórico singular e pela sua diversificada paisagem natural.

5 Os processos de mobilização social não serão aqui aprofundados, mas é importante lembrá-los, visto que a equipe do Polo sempre realiza e planeja as atividades visando à corresponsabilidade dos jovens. Os participantes, colocados como protagonistas são levados a se sentirem construtores de novos produtos e, mais que isso, como importantes transformadores de uma realidade local.

${ }^{6} 0$ portfólio digital está disponível em: <http://www.ciadeteatroicaros.wix.com/portfolio $>$.

7 Por estar atrelado às urbes, o cordel se direciona ao que é "vulgar" (MARTÍN-BARBERO, 2009, p. 155), ou seja, "aquilo que se move na cidade, vulgar é o plebeu e o vagabundo, o desviado e o contaminado" ( $p$. 155). De maneira intrigante, o cordel destacava-se pela identificação com as classes populares, que, justamente, possuíam menos contato com a cultura erudita e com o mundo letrado. Pode-se dizer que o cordel fascinava as pessoas que não sabiam ler. Fazia ler os analfabetos e, ainda hoje, influencia na produção midiática, como na de jornais, telenovelas e músicas.
} 
Do Vale para o Vale: uso colaborativo dos meios como forma de reforçar vínculos

From the Vale to the Vale: collaborative use of medias as a way to reinforce bonds

\begin{abstract}
This paper presents some perspectives to discuss how the communication workshops realized within the Programa de Férias (Summer Program) coordinated by the Polo de Integração of UFMG in the Jequitinhonha Valley (PROEX/UFMG) and by the Public Relations Laboratory Plinio Carneiro (LARP/UFMG), encourages the recognition and the valorisation of the region by the youth that lives in the Jequitinhonha Valley and that participates in extensions activities. In the first section of the paper, we propose to discuss three hubs: the use of the media, the production of collaborative communication and the local space. In the second section we present workshops that were developed in the Programa de Férias (Summer Program) to exemplify the debate towards the collaborative use of the media as a way to reinforce bond of belonging in the relations between subjects and their local space.
\end{abstract}

\section{Keywords}

Communication; Youths; Access to the media Collaboration; Location.

Original submetido em: 14 jun. 2015

Aceito para publicação em: 25 jul. 2015
Del Vale hacia el Vale: el uso colaborativo de los medios de comunicación como forma de fortalecer los lazos

\section{Resumen}

El artículo desarrolla algunas perspectivas para discutir cómo talleres de comunicación celebrados en el Programa de Férias (Programa de Vacaciones), coordinado por el Polo de Integração da UFMG no Vale do Jequitinhonha (PROEX/UFMG) y el Laboratório de Relações Públicas Plínio Carneiro (LARP/UFMG), estimulan el reconocimiento y la valoración de la Región por los jóvenes residentes en el Vale do Jequitinhonha que participan de las actividades de extensión. En la primera parte del texto, se propone discutir tres áreas: el uso de los medios de comunicación, la producción de la comunicación colaborativa y el espacio local. En la segunda, se presentan algunos de los talleres desarrollados en el Programa de Férias (Programa de Vacaciones) para ilustrar el debate sobre el uso colaborativo de los medios de comunicación con el fin de fortalecer los vínculos de pertenencia en la relación entre los sujetos y su espacio local.

\section{Palabras clave}

Comunicación; Jóvenes; El acceso a los medios de comunicación; Colaboración; Local.

Sobre os autores:

\section{Raissa Fernandes Faria}

Bacharel em Comunicação Social: Relações Públicas (UFMG). Bolsista de Extensão do Suporte de Comunicação do Polo de Integração da UFMG no Vale do Jequitinhonha no período de 1 jul. 2012 a 30 jun. 2013.

\section{Tomás German}

Estudante de Comunicação Social: Publicidade e Propaganda (UFMG). Bolsista Bolsista de Extensão do Suporte de Comunicação do Polo de Integração da UFMG no Vale do Jequitinhonha no período de 1 mar. 2012 a 31 dez. 2013.

\section{José Henrique Pires}

Estudante de Comunicação Social: Jornalismo (UFMG). Bolsista Bolsista de Extensão do Suporte de Comunicação do Polo de Integração da UFMG no Vale do Jequitinhonha no período de 1 mar. 2013 a 31 dez. 2013. 